\title{
Alarming visual display monitors affecting shower end use water and energy conservation in Australian residential households
}

\author{
Rachelle M. Willis \\ Ph.D. Candidate, Griffith School of Engineering, Griffith University \\ Gold Coast Campus, Queensland 4222, Australia \\ r.willis@griffith.edu.au \\ Dr. Rodney A. Stewart \\ Senior Lecturer, Griffith School of Engineering, Griffith University \\ Gold Coast Campus, Queensland 4222, Australia \\ r.stewart@griffith.edu.au \\ Dr. Kriengsak Panuwatwanich \\ Lecturer, Griffith School of Engineering, Griffith University \\ Gold Coast Campus, Queensland 4222, Australia \\ k.panuwatwanich@griffith.edu.au \\ Sarah Jones \\ Coordinator Demand Management, Gold Coast Water \\ PO Box 5042, Gold Coast Mail Centre, Queensland 9729, Australia \\ SJONES@goldcoastwater.com.au
}

\section{Andreas Kyriakides}

Research Assistant, Griffith School of Engineering, Griffith University

Gold Coast Campus, Queensland 4222, Australia

a.kyriakides@griffith.edu.au

\section{Corresponding Author:}

Dr. Rodney Stewart

Senior Lecturer

Griffith School of Engineering

Gold Coast Campus, Griffith University

Email: r.stewart@griffith.edu.au

Ph (work): +61 755528778

Ph (mob): +61 0409788173 


\title{
Alarming visual display monitors affecting shower end use water and energy conservation in Australian residential households
}

\begin{abstract}
Sustainable urban water consumption has become a critical issue in Australian built environments due to the country's dry climate and increasingly variable rainfall. Residential households have the potential to conserve water, especially across discretionary end uses such as showering. The advent of high resolution smart meters and data loggers allows for the disaggregation of water flow recordings into a registry of water end use events (e.g. showers, washing machine, taps, etc.). This study firstly reports on a water consumption end use study sample of 151 households conducted in the Gold Coast, Australia, with a focus on daily per capita shower end use distributions. A sub-sample of 44 households within the greater sample was recruited for the installation of an alarming visual display monitor locked at 40 litres consumption for bathroom showers. All sub-sample shower end use event durations, volumes and flow rates were then analysed and compared utilising independent sample $t$-tests pre- and post intervention. The installation of the shower monitor instigated a statistically significant mean reduction of 15.40 litres (27\%) in shower event volumes. Monetary savings resulting from modelled water and energy conservation resulted in a 1.65 year payback period for the device. Furthermore, conservative modelling indicated that the citywide implementation of the device could yield $3 \%$ and $2.4 \%$ savings in total water and energy consumption, respectively. Moreover, a range of non-monetary benefits were indentified, including the deferment of water and energy supply infrastructure, reduced resource inflationary pressures, and climate change mitigation, to name a few. Resource consumption awareness devices like the one evaluated in this study assist resource consumers to take ownership of their usage and individually tackle individualistic and/or society driven conservation goals, ultimately helping to reduce the ecological footprint of built environments.
\end{abstract}

Keywords: smart meters, water conservation, energy conservation, water end use, resource consumption display monitors, water demand management 


\section{Background}

\subsection{Climate change and improving urban water security}

In many parts of the world, an escalating demand on potable water resources resulting from increasing populations has become commonplace (Willis et al. 2009). While this has triggered higher water consumption, water availability is also becoming increasingly variable due to the global change of climate (Inman and Jeffrey 2006). In Australia, a recent drought period between 2001 and 2004 touched most of the continent and demonstrated the severe localised impacts of climate change. Moreover, after almost five years of continued lower-than-average rainfall across most of the eastern part of the Australian continent, many Australian cities and towns continue to face drought conditions with some water supply reservoirs at their lowest recorded levels.

A recent report by the Australian National Climate Centre showed trend annual rainfall decreasing by up to 50mm per year over the southern half of the continent (CSIRO, 2007). Coupled with such water scarcity is increasing urbanisation, which intensifies the concern over the existing urban water resources and places a strain on future water security. A study by Birrell et al. (2005) on the impact of demographic change and urban consolidation on domestic water use in Australian cities revealed that, during 2001-2031, water demand in major cities will increase by an average of 37\%. Such evidence of dwindling supplies and increasing demand has triggered water industries and all levels of government to seriously reconsider the management of water resources in Australia. Hence, a significant investment in adequate planning and the adoption of smarter approaches to water management is required to ensure a sustainable water future.

From a worldwide perceptive, many governments and public utilities who are similarly affected by water crises, are investing significant funds in the development and implementation of water strategies to ensure future water demands can be met. Predictions and estimations of future demand and potential savings through the introduction of demand management strategies or source substitution options are now commonplace. Demand management strategies include water metering, water restrictions, rebate programs for water efficient devices, water efficiency labelling, water conservation or education programs and pressure and leakage management (Inman and Jeffrey 2006). Source substitution or 'fit for use' water 
involves replacing specific potable end uses such as toilet flushing and irrigation with recycled, grey or storm water. Water savings achievable from such programs are calculated through a variety of assumptions but, once in place, limited consideration is given to determining the actual water savings associated with these strategies. It is well documented that more data and information should be collated on the effectiveness and sustainability of demand management techniques, to improve long term forecasting (Chambers et al. 2005). After decades of inadequate metering of water use, organisations have come to the realisation that it is impossible to manage water resources without having adequate measuring and monitoring practices (Hearn 1998).

\subsection{Domestic water consumption and conservation}

Residential water consumption can account for up to $66 \%$ of the total supplied water as was the case at the Gold Coast, Australia in the 2007-2008 monitoring period. Residential water consumption has previously been determined to be effected by seasonal changes and water demand management (WDM) strategies such as water metering, water restriction levels, water efficient devices and education (Inman and Jeffrey 2006; Mayer et al. 2004; Nieswaidomy, 1992). Although prior research has occurred, it is well established that there is a need for specific country and location based research as different community attitudes and behaviours can influence the effectiveness of WDM strategies (Corral-Verdugo et al., 2002; Turner et al. 2005). To grasp the effectiveness of WDM strategies high quality data is required, hence the development of smart metering techniques.

\subsection{Advent of smart water metering and end use analysis}

The need for smart water metering stemmed from the fact that traditional systems do not provide real-time water consumption data or sufficient data points to determine usage patterns. Conventional water meters count litres of water as it passes through the meter without the ability to record when (i.e. time of day) and where the consumption takes place (e.g. clothes washing, leakage, shower use, etc.). Water consumption readings are generally recorded manually on a quarterly or half yearly basis. Under most situations, a whole year's worth of water consumption data is described by only two to four data points (Britton et al., 2008). No further information is available to draw upon should there be any queries (Hauber-Davis and Idris, 2006). Obviously, this conventional water metering system produces limited, delayed water consumption 
information and is unable to provide effective support for water planning and management processes. Moreover, it is not adequate to meet the increasing level of government scrutiny on the utilisation of water resources or the effectiveness of WDM strategies and does not assist society at large to address the pressing water security issues associated with climate change.

The concept of smart metering embraces two distinct elements: (1) meters that use new technology to capture water use information; and (2) communication systems that can capture and transmit water use information as it happens, or almost as it happens. Smart water meters essentially perform three functions; they automatically and electronically capture, collect and communicate up-to-date water usage readings on a real-time basis (Idris, 2006). To achieve this objective, the reed switch on traditional volumetric water meters is modified to collect a high resolution record of water use (i.e. from the traditional 2 to 72 pulses per litre or 0.014 litres per pulse) which can then be disaggregated into individual water use events using a flow trace analysis software tool (e.g. Trace Wizard@). The high resolution water measurement information from the meter is then captured by attached high data capacity loggers (i.e. 2 million readings) recording information at a pre-set time interval (e.g. 5 seconds). Time scaled flow recording information is then collected in-situ through infrared cables or wirelessly through a mobile phone network. Once a representative sample of data is collected, the flow trace analysis software tool is applied to disaggregate flow traces into a list of component events assigned to a specific end use appliance or fixture (e.g. shower, toilet, clothes washing, etc.). Stock and behaviour surveys can also be utilised to help the analyst develop templates which encapsulate the appliance properties of end use events and ensure accurate end use categorisation. Once analysis has been completed a database registry of all end use events occurring during the sampled period is established and can subsequently be utilised for water planning and management research as demonstrated herein.

Hence, a smart meter is a high resolution water meter (e.g. 72 pulses per litre) linked to a device (a data logger) that allows for the continuous reading of water consumption. Smart metering allows for communication of captured data to a broad audience, e.g. utility managers, consumers and facility authorities. Smart metering is an established technology which is now cost-effective enough to be applied to collect, store and distribute real-time water consumption data (Hauber-Davis and Idris, 2006). An 
automated meter reading system with this capability provides benefits for both consumers and water authorities for monitoring and controlling water consumption. Understanding and collecting empirical evidence of where and how water is used, through smart metering, allows planners and conservationists to determine the relative water saving of WDM strategies.

\subsection{Engineered water conservation appliances and fixtures}

The development of water efficient devices such as low flow shower roses or dual flush toilets has led to effective water savings within households. Several studies have been undertaken to determine the relative water savings attributed to the installation of engineering water conservation fixtures and appliances. The replacement of high water consuming devices with those of engineered water efficiency has resulted in indoor water consumption savings between 35 - 50\% (Inman and Jeffrey 2006; Mayer et al. 2004).

A variety of water saving devices are available on today's market which attempt to reduce water end use consumption. Such devices include toilet dams, AAA rated shower roses, dual flush toilets (3/4.5 L/flush), water pressure limiting devices, and tap aerators, to name a few. With respect to showers, the trend of lower shower consumption volumes with more efficient devices has previously been established by Mayer et al. (2004). In more recent times, the development of visual display technologies and alarming devices designed to influence both water and energy conservation responses at the end use level have become more readily available. Therefore, in addition to retrofitting appliances and fixtures with those of a higher efficiency, such display technologies provide a dynamic feedback to resource consumers, ultimately influencing behaviours.

\subsection{Visual display technologies and alarming devices influencing resource conservation behaviour}

While houses with water saving devices typically demonstrate reduced end use water consumption, evidence also which indicates that engineered savings can often be diminished by human behaviour. For instance, a study by Inman and Jeffrey (2006) resulted in an increase in water consumption after the installation of water saving devices. This was due to the resident's misguided belief that they were saving water through their efficient devices and hence took longer showers which often resulted in higher consumption volumes. The "Human Exception Paradigm" is a basic belief that humans are above nature 
and therefore do not have to regard it as they consume resources (Bechtel et al., 1999). Thus, these primitive beliefs can serve to inhibit conservational behaviour. A study into the link between environmental behaviour and water conservation behaviour determined that general environmental beliefs affected the specific beliefs regarding the use of water, which in turn, correlated with the measure of water consumption (Corral-Verdugo et al., 2002). Waisbord (1999, p. 2) states that 'interventions are needed to provide people with information to change behaviour' and that it is a lack of knowledge which contributes to problems in development. Education is a key component for changing behaviour and attitudes towards water use (Webb, 2007). If people are made aware of their water usage, more importantly their water wastage, they are much more likely to actively reduce their consumption.

Essentially, the use of electronic visual and/or alarming monitoring devices provides immediate feedback to resource users. Compared with written feedback such as quarterly bills, electronic devices provide quicker and more frequent feedback, thus better informing the consumer of the consequence of their specific behaviours (Midden et al., 2007; Darby, 2006). It is especially effective when information is given frequently which is the case with continuous electronic feedback (Abrahamse et al., 2007). In general, feedback enables people to be more conscious of the relevance and affect of their own behaviour. When resource consumption is closely linked to specific appliances and activities, the relevance and direct affect of behaviour becomes clearer. Through appliance-specific feedback, the consumer can determine how a certain appliance or a particular way of using it affects the amount of water or energy resource consumed. This allows the consumer to curb poor behaviours and to use resource consuming appliances more effectively to achieve higher savings and shift towards sustainable consumption habits (Fisher, 2008).

In the electricity sector, immediate feedback through electronic devices has been regarded to be very effective in helping to conserve energy (Wood and Newborough, 2003; Fischer, 2008). Specifically, electronic visual displays have proven to be useful in promoting energy conservation behaviour in people, based on extensive research conducted worldwide. In the US, McClelland and Cook (1979-1980) carried out a study using the Fitch Energy Monitor (FEM) that displays the total electricity usage and reported a $12 \%$ reduction in electricity usage in households with the FEM compared with those without it. Similarly, in Canada, Dobson and Griffin (1992) investigated the use of the Residential Electricity Cost Speedometer 
(RECS) system, which measured household electricity consumption and presented cost and electricity consumption for various end uses displayed on an hourly, daily, monthly and annual basis. The results showed that the use of the RECS system helped reduce the average daily energy consumption by $12.9 \%$. The above findings appear to be consistent with those found in Japan by Ueno et al. (2005, 2006), who conducted a series of experiments on the use of a computerised interactive "energy consumption information system" that displays daily energy consumption for all the domestic appliances within a household. They found that the use of such a tool led to $9-12 \%$ reduction in power consumption, and that energy-conservation awareness affected not only the power consumption of the appliances explicitly shown on the display monitor, but also other household appliances implying a change in consumption behaviours. In the UK, Wood and Newborough (2003) compared the effectiveness of providing paper-based energyuse/saving information with electronic feedback of energy-consumption via smart meters and energy consumption indicator (ECI) displays. The findings showed that the average reduction for households employing an ECI was 15\%, whereas those that were only given paper-based energy saving information reduced their electricity consumption, on average, by only $3 \%$.

In the water sector, research on the impact of visual displays and alarming devices on water conservation is still limited. In the US, Arroyo et al. (2005) developed a device called “WaterBot” that presents immediate feedback in the form of visual and auditory reminders. The device is to be installed on household faucets to motivate people to turn off the tap when the water is not being used. Although there has been no systematic experiment conducted to quantify the water savings from installing the device, pilot studies through observations and user reports suggested a behavioural change that could reduce water consumption by the presence of the device. Recently, Kappel and Grechenig (2009) developed a shower water meter (show-me) that displays the amount of water used during one shower in the form of LEDs assembled on a stick, and installed the device in several households in Austria. The results showed a decrease in the mean shower water consumption of approximately 10 litres. This suggested a promising water saving potential in the shower with regards to using visual displays for delivering feedback.

In the case of this study, the WaiTEK ${ }^{\circledR}$ Shower Monitor $\bigodot$ is an innovative device that provides the alarming visual feedback intervention (Fig. 1). This educational engineering device provides a digital read- 
out of shower parameters such as flow rate, duration and temperature. While most water saving devices physically limit the volume or flow rate of water that can be used, this monitor does not affect the shower in any way. Rather, it simply provides the information necessary to allow households to shower more efficiently. At the end of the predetermined shower duration, it will beep for duration of one minute to indicate that it is time to get out of the shower. This device aims at educating the public on their shower water consumption as it is essential to encourage and develop behaviour leading towards sustainable water consumption. Therefore the effectiveness of the monitor far supersedes any other water saving device on the market as it addresses the underlying issue of first changing the beliefs and behaviours of the shower users, rather than simply enforcing a restriction. Armed with this information, shower users can supervise their own habits to ensure they adequately conserve water.

\section{[INSERT FIGURE 1]}

\subsection{Overview of Gold Coast Watersaver End Use study}

Currently, there are no end use water consumption models for the urban South-east Queensland (SEQ) region of Australia. This region has a sub-tropical climate and has recently experienced severe drought conditions, forcing both State and Local Governments to develop numerous strategies to reduce water usage. In this respect, gaining empirical evidence of how and where water is used and determining the effectiveness of specific WDM strategies is critical for planners, utilities and conservation professionals. This information can be used to improve the design of conservation programs and can provide justification for continued support of conservation efforts (Mayer and DeOreo, 1999). As mentioned, per capita consumption varies significantly throughout regions within the world, hence the need for location and country based research is necessary to determine the effectiveness of WDM (Inman and Jeffrey, 2006; Turner et al., 2005). In addition, it has been acknowledged that community attitudes and behaviours can also influence the effectiveness of water savings resulting from WDM strategies (Corral-Verdugo et al., 2002). In the US, Mayer and DeOreo (1999) have explored some relationships between water consumption and demographic variables at the end use level. Their research suggested that demographic variables such as family size and age distribution, wealth or income, ownership status and household attitudes towards using and conserving water, influence household water consumption (Mayer and DeOreo, 1999; Kenney et 
al., 2008; Turner et al., 2005; Taverner Research, 2005). However, in Australia, there has been minimal research on investigating end use water consumption with relation to demographic variables within monitored homes.

Motivated by the above research demand, Griffith University and Gold Coast Water have collaborated under an Australian Research Council (ARC) grant to conduct an investigation of end use water consumption in the Gold Coast region. This investigation is aptly named the Gold Coast Watersaver End Use (GCWSEU) study. Other primary objectives of the research are to examine the effectiveness of dual reticulation and education as potable water saving mechanisms. Dual reticulation is a water supply system which consists of two separate main supplies to the consumer: one drinking or potable water; and the other non-drinking or recycled water (WSAA, 2002). The research also aims to establish a dataset which compiles end use water consumption data, demographic information, and attitudinal data. As stated by Kenney et al. (2008), the collection and integration of these datasets, especially household level consumption data with demographic data about the people and house, rarely occurs. The utilisation of these datasets allows for the investigation of the effect of demographic variables, attitudes and behaviours on water consumption.

This paper reports findings from the pre-intervention phase of the study, which included the winter 2008 end use data for 151 households along with the water end use for shower events post implementation of the WaiTEK® Shower Monitor@ (Fig. 1). Study objectives and the scope of the herein focused study are presented below.

\section{Research objectives}

WDM and 'fit for purpose' water consumption has changed the current focus to demand, rather than supply side measures, to meet the ever increasing requirement on diminishing water resources. WDM strategies such as water metering, water restrictions, rebate programs for water efficient devices, water efficiency labelling, water conservation education programs, and the application of recycled, grey and stormwater for specified end uses have been introduced throughout Australia and the world. However, water authorities 
still have vague indications on the effectiveness of these programs. This paper provides an in-depth investigation into an alarming visual display device, namely the WaiTEK ${ }^{\circledR}$ Shower Monitor $@$, on shower water end use properties.

The key objectives of this research are to:

- Determine baseline water consumption end uses for a sample of households;

- Establish baseline shower end use event characteristics (e.g. volume, duration, flow rate) for 151 households in the Gold Coast residential end use study;

- Evaluate the water savings potential of the WaiTEK® Shower Monitor@ in a sub-sample of households participating in the GCWSEU study;

- Determine households' response to the alarming visual display device through reduced, or otherwise, shower durations or flow rate;

- Quantify water and energy savings (i.e. hot water for showering purposes) achieved in the subsample;

- Model the payback period and annualised return for the device; and

- Model the monetary and non-monetary benefits achievable from the citywide implementation of the device.

Research outcomes provide water authorities and government officers with the decision support systems to accurately predict the monetary and non-monetary benefits of installing such alarming visual display devices; ultimately preserving water sustainability. The research method adopted to achieve the above mentioned objectives are described below.

\section{Research method}

The greater GCWSEU study participants ( $\mathrm{N}=151)$ were recruited through a multi-staged process of letters and door knocking. Selection of participants was based on a number of criteria including: household ownership status (renting/owning) and household makeup; willingness to be part of the research for a 
period of two years; acceptance to having water consumption monitored over period; several questionnaire surveys; involvement in a range of potential interventions; and involvement in a household water fixture/appliance stock audit. It should also be noted that historical household volumetric readings were analysed for the consenting sample to ensure that they are representative of Gold Coast City.

Upon completion of recruitment, the existing standard residential water meters were replaced with high resolution water meters and data loggers to obtain end use water consumption data. The modified Actaris CTS-5 water meters pulse at a rate of 72 counts per litre of water consumed; this equates to an individual recording every $0.014 \mathrm{~L}$ of water use. Aegis DataCell D-CZ21020 data loggers were connected to water meters to record water consumption. Data loggers were set to record information every ten seconds over a two week period. This resulted in fourteen days of end use data for each household. Trace Wizard $\subset$ software was utilised to synthesise data into water end uses. This software provides the analyst with powerful processing tools and a library of flow trace patterns for recognising a variety of residential fixtures. Once the raw data has been downloaded from the data logger and processed, it can then be loaded into Trace Wizard@. This software displays the data via a flow rate verse duration graph, whereby any consistent flow pattern or event can be isolated, quantified and categorised based on an established series of end use templates with specific information regarding a particular household's water usage patterns. Summary data for each water event is then calculated, including, duration, volume, peak flow rate, mode flow rate, mode flow frequency, as well as start and stop times for each episode. The software also has the ability to recognise two simultaneous events. Once analysis has been completed, the file is converted to a database format, whereby a complete registry of end use event information is stored. For the purposes of this study, this database allowed researchers to create relative and cumulative frequency distributions for shower end use event durations, volumes and flow rates.

The baseline data utilised in this paper was collected during winter 2008. During this time there were no water restrictions in place on the Gold Coast as its primary water source (i.e. Hinze Dam) was higher than 95\% capacity. In total, the 151 monitored households included 38 single reticulated and 113 dual reticulated water supplies. It should be noted that recycled water was not supplied to the dual reticulated region during the monitoring period as the treatment plant had not been commissioned. Thus, potable water 
was supplied to the appropriate end uses (i.e. toilet and selected outdoor taps), which in the future (late 2009) will be supplied by recycled water. Shower end use is only ever supplied by potable water, thus the affect of dual reticulation has no bearing on the study’s objectives and subsequent outcomes.

In addition to monitoring water consumption, questionnaire surveys soliciting descriptive information were developed and distributed to all the sample households. Surveys were conducted to solicit household demographic information, including: (1) household address and region; (2) resident numbers, gender, age, employment, weekly income, education status and relationship of people within the house; and (3) household ownership status. Household stock surveys were also conducted to ascertain the nature of water fixtures and appliances as well as hot water heating systems.

A sub-sample from the 151 households in the GCWSEU study was recruited to participate in the herein mentioned shower monitor retrofit study. A total of 49 households consented to be apart of this aligned sub-study and have shower monitors fitted to their utilised showers. The initial sub-sample total water consumption and shower end use data, along with their socio-demographic statistics was screeded to ensure that the final selected sub-sample was as representative of the population as possible (given the feasible sample size). Five consenting households were removed as the initial sub-sample was over represented by retired couples. Upon completion of the recruitment and sample screening process, a total of 44 households were included in the sub-sample, and all of their utilised showers were fitted with the alarming visual display device (Fig. 1) that was locked to a 40L shower event (i.e. based on a 5 minute shower at a flow rate of $8 \mathrm{~L} / \mathrm{min}$ ). The device was set to alarm after the $40 \mathrm{~L}$ volume was consumed so individuals would know when it was time to get out of the shower. The monitor is programmed to automatically turn on once water is flowing through the shower. The monitor displays a bar graph which decreases over time of water consumption. Monitors were also set for a delay time of 1 minute. The delay time is the time in which the person must wait between showers so that the monitor can reset itself. If a person starts another shower before the 1 minute is over, the monitor will start beeping. The shower monitors were all locked with a 4digit pin code that was retained by the researchers for study period to ensure that settings were not changed. The monitor does not control the shower in any way. Instead, its purpose is to help families reduce water and energy costs by providing the information necessary for them to shower efficiently. Ultimately, the 
participants have the choice of getting out of the shower when the beeping occurs or to simply ignore it and continue showering. Specifically, the device aims to educate families on sensible water consumption by empowering the consumer with real-time information rather than constructing a military type environment.

Following the implementation of the shower monitors water end use data was collected over a two week period in winter 2009, following the same process described above for the baseline GCWSEU study. Analysed and verified trace analysis files for the pre- and post- shower monitor retrofit were converted to database files whereby all shower events could be listed and categorised based on event duration (based on event start and end time), volume or flow rate. Relative and cumulative frequency distributions for subsample shower event characteristics were then established along with as their associated mean, median and standard deviation values. This data analysis process enabled shower event comparisons to be conducted pre- and post- installation of the shower monitor. The baseline water consumption end use results, with a particular focus on shower end use is presented in the next section, followed by the comparative assessment pre- and post- implementation of the shower monitor.

\section{Baseline water consumption end use analysis}

The break down of end use water consumption for the sampled households in the Gold Coast $(\mathrm{N}=151)$ for winter 2008 is presented in Fig. 2. Readers should again note that recycled water is not currently supplied to the dual reticulated region as the treatment plant was not commissioned. Thus, potable water was being supplied to appropriate end uses (i.e. toilet and outdoor taps) which in the future (i.e. late 2009), will be supplied by recycled water. Due to this fact, the cost for this water is the same as potable (i.e. no reduced pricing) and the water restriction level remains constant between the regions. Moreover, no awareness campaign was launched to encourage the uptake of recycled water in the dual reticulated region. Considering this current situation and the limited variance between the applicable end uses of single and dual reticulated households, the two datasets was treated as one sample for the purpose of this present study (Willis et al., 2009). Once recycled water is commissioned, it is expected that there will be a clear distinction between the single and dual reticulated households, predominately due to higher irrigation use within the latter sample. 


\section{[INSERT FIGURE 2]}

According to Fig. 2, the average baseline consumption for the sampled Gold Coast households ( $\mathrm{N}=151)$ was 157.2 litres per person per day $(\mathrm{L} / \mathrm{p} / \mathrm{d})$. The highest end use was showering, with each person consuming almost 50 litres of water a day or 33\% of total use. Clothes' washing was the next highest end use at $30 \mathrm{~L} / \mathrm{p} / \mathrm{d}$ or $19 \%$ of total consumption. Tap use, toilet flushing and irrigation follow with end use percentages of $17 \%, 13 \%$ and $12 \%$, respectively. Bath use, dishwashing and leaks make up a small component of water end use with percentages ranging from $1 \%$ to $4 \%$. Many of the prior mentioned end use studies show irrigation consuming a higher proportion of the total household water consumption, especially in summer months. The Gold Coast is located in a region experiencing a humid subtropical climate, where irrigation consumption is generally lower in the wet summer months than other seasons. Moreover, the study was conducted just after a period of drought where irrigation was severely restricted; after this drought there was a culture shift whereby brown grass was accepted in dry periods.

Fig. 3 demonstrates the descending order distribution of the end use water consumption break down for each of the measured 151 households. It also shows the proportion of sampled households within each of the Queensland Water Commission (QWC) restriction regime categories, upon which the Gold Coast Local Government Area (LGA) must conform (i.e. Target 140: Extreme Level; Target 170: High Level; Target 200: Medium Level; and Target 230: Permanent Water Conservation Measures). The average total consumption of sampled households in the study and distribution are representative of the Gold Coast at the time of study.

\section{[INSERT FIGURE 3]}

Whilst there were no restrictions at the time on the Gold Coast, almost half of the research population (46\%) consumed less than $140.0 \mathrm{~L} / \mathrm{p} / \mathrm{d}$. Water consumption is highly varied between individual households. The highest per capita use equated to $390.0 \mathrm{~L} / \mathrm{p} / \mathrm{d}$ whilst the lowest use was as small as $38.4 \mathrm{~L} / \mathrm{p} / \mathrm{d}$. This substantial difference between the highest and lowest per capita consumption volumes demonstrates that a 
representative spread of water users is present in this research sample. Fig. 3 illustrates that shower end use in many households is the major contributor to the total water consumption level. The extracted water end use distribution of this specific activity is presented in Fig. 4.

\section{[INSERT FIGURE 4]}

Fig. 4 shows that $13 \%$ of the sampled households consumed $30 \%$ of the total volume of water utilised for showering purposes. This highlighted sub-sample (13\%) constitutes a non-linear shower use pattern as opposed to the remaining research population (87\%) which shows a reasonably linear rate of change in consumption. The distribution of shower use, as illustrated in the Fig. 4 insert, demonstrates that half of the population used less than $40 \mathrm{~L} / \mathrm{p} / \mathrm{d}$ of water for showering which is equivalent to a 5 minute shower at 8L/min. For the remaining categories, $37 \%$ of households use between 41 to $80 \mathrm{~L} / \mathrm{p} / \mathrm{d}$ with the high user group (13\%) consuming on average more than $80 \mathrm{~L} / \mathrm{p} / \mathrm{d}$ in the shower. The high level of shower end use consumption and its variability identified in the baseline study instigated the design for the shower monitor intervention study described in the next section.

\section{Visual display monitors influencing shower end use events}

As described in the research method, the categorised shower end use event features were compiled into a database for both the pre- and post- shower monitor implementation. Three of the shower event features, namely, event duration, volume and flow rate, were summarised in a clustered relative and cumulative frequency distribution histogram. Moreover, the mean and median values for these features pre- and postimplementation of the shower monitor were determined and compared. It should be specially noted that changes in flow rates before and after shower monitor retrofits were of concern since the study sought to understand whether households would reduce flow rates to maximise their shower duration before an alarm sounded. As mentioned previously, readers should note that the fixed 40L volume is a function of flow rate and duration and the device compensates for variation in these variables. The following sections provide the results and discussion relating to changes in shower duration, volumes and flow rates, respectively. 


\subsection{Influence on shower duration}

The change in the relative and cumulative frequency distribution for shower event durations is illustrated in Fig. 5. The figure illustrates that post installation there is a much higher frequency of shower event durations between 1-7 minutes. It appears that many of the 7-15 minute shower events have moved into these lower interval categories. Given that the shower monitor was locked to beep after 40L with approximate shower duration of 5 minutes it seems that many home owners still shower for a minute or two after the beeping commences. The data shows that households that were originally water conscious have further reduced their consumption with a significant increase in showers in the 1-4 minute intervals. Whilst the frequency of shower events greater than 10 minutes has more than halved from $14 \%$ to $6.4 \%$, the results indicate that some residents still continue to have excessively long showers even with a visual display and alarm present.

Nonetheless, as indicated in the inset of Fig. 5, the mean shower duration reduced from 7.19 to 5.86 minutes, which equates to a saving of 1 minute and 20 seconds (i.e. 1.34 minutes) or $18.6 \%$. An independent sample $t$-test for equality of means was undertaken to test the significance of mean differences (Table 1). Independent rather than paired sample $t$-tests were undertaken since the total number of shower events in the sub-sampled households' pre- and post- retrofit was obviously different and were treated as two samples. According to Levene's test for equality of means the samples were treated as having unequal variances. The independent unequal variance sample two-tailed $t$-test resulted in a very high $t$-value of 6.62 $(p<0.0005)$ indicating significant mean value differences. The lower difference between the median shower event durations (i.e. 50 seconds) indicates that the long tail of high duration events increased mean values. This fact is reinforced by the samples standard deviation being very high (i.e. 4.49 minutes preretrofit and 3.55 minutes post-retrofit), however, noticeably reduced post retrofit of the shower monitor. In summary, the shower monitor reduced the time spent in the shower, but not to the extent expected with the device alarming at 5 minutes based on the set $8 \mathrm{~L} / \mathrm{min}$ flow rate. Residents may have decided to reduce their typical shower flow rate to yield a longer event duration (i.e. reducing flow rate below $8 \mathrm{~L} / \mathrm{min}$ will increase duration beyond 5 minutes before alarm sounds); this will be explored later.

\section{[INSERT FIGURE 5]}


[INSERT TABLE 1]

\subsection{Influence on shower volumes}

Fig. 6 details the relative and cumulative frequency of shower event volumes pre- and post- implementation of the shower monitor. The figure illustrates that even prior to the implementation of the shower monitor, $39.9 \%$ of the shower event volumes were less than $40 \mathrm{~L}$ increasing to $59.3 \%$ after the implementation of the shower monitor. It appears that shower users already practicing water conservation went even further in reducing shower volumes as many of the $30-40 \mathrm{~L}$ events probably reverted to the $10-20 \mathrm{~L}$ or $20-30 \mathrm{~L}$ intervals. Another interesting characteristic of the histogram is the reduction in shower events in the 60100L range post-retrofit but the slight increase in the 40-50L interval. It appears that a reasonable proportion of residents that previously showered within the 50-100L range now responded within a minute or so of the alarm and finished their shower. Unfortunately, even after the shower monitor retrofit $4.5 \%$ of the shower event volumes were greater than 100L. Again, it is evident that some residents having very high consumption shower events were not perturbed by the shower display and alarming device.

As indicated in the inset of Fig. 6, the mean shower event volume decreased from 57.37L to 41.97L after the shower monitor retrofit. This resulted in a saving of $15.40 \mathrm{~L}$ per shower event or $27 \%$. An independent sample $t$-test for equality of means was undertaken to test the significance of mean differences (see Table 1). According to Levene's test for equality of means the samples were treated as having unequal variances. The independent unequal variance sample two-tailed $t$-test resulted in a very high $t$-value of 8.93 ( $p<$ 0.0005) indicating significant mean value differences. Of note also is that the median shower event fell below the 40L target after the implementation of the shower monitor (i.e. 36.38L). The improvement in shower event volumes is reinforced by the significant drop in standard deviation from 40.36L to 27.33L per event (i.e. 13.03L reduction). The results for shower event volumes indicate that the shower monitor had a good degree of impact on reducing shower water consumption to a mean value close to the targeted 40L; this is a promising result considering that the tail of high volume showers evident in the relative frequency distribution histogram (Fig. 6). 


\section{[INSERT FIGURE 6]}

\subsection{Influence on shower flow rates}

Fig. 7 details the shower event flow rate relative and cumulative frequency distribution for the sampled households. Cumulative flow rate frequency distributions between 0-8 minutes increased from 40.7 to $52 \%$ indicating that some residents were aware that reduced flow rates would increase their shower duration before the visual display monitor alarmed. In general, the relative frequency distribution histogram provides some evidence that residents have slightly lessened flow rates from their baseline. Exactly $1 \mathrm{~L} / \mathrm{min}$ or $10.2 \%$ was reduced from the mean flow rate post shower monitor implementation (i.e. 9.78 to 8.78L $/ \mathrm{min}$ ) and a slightly lower reduction in the median flow rate was evident. An independent sample $t$ test for equality of means was undertaken to test the significance of mean differences (see Table 1). According to Levene's test for equality of means the samples were treated as having unequal variances. The independent unequal variance sample two-tailed $t$-test resulted in a very high $t$-value of 5.78 ( $p<$ 0.0005) indicating significant mean value differences. In summary, the relative frequency distribution provides an indicator that some residents understood how the device worked and reduced their flow rates in order to extend shower duration. Additionally, the mean as well as median flow rates are still above the targeted 8L/min strived for but have nonetheless reduced along with variance. The following section provides a discussion on the water and energy savings, monetary savings and payback period, and nonmonetary benefits, derived from the implemented shower monitoring device.

[INSERT FIGURE 7]

\section{Resource conservation and financial modelling}

\subsection{Water and energy conservation}

As determined in this study the shower monitor interventions reduced the sub-samples shower event volume by $15.40 \mathrm{~L}$ or $27 \%$. Based on the Gold Coast end use study sample $(\mathrm{N}=151)$ as well as the postimplementation sub-sample end use data, the average number of shower events per household per day was determined to be 2.65 . Therefore, given the $15.40 \mathrm{~L}$ saving per shower event and mean 2.65 shower events 
per household per day, a daily 40.85 litres per household per day (L/hh/d) or 14.91 kilolitres per household per annum (kL/hh/a) saving can be achieved. There are approximately 200,000 occupied dwellings in Gold Coast City. Conservatively estimating that $50 \%$ of the determined water savings are achieved in the cities dwelling stock due to a range of factors (e.g. household size, etc.), a total citywide annual saving of 1.5GL or $3 \%$ of total city consumption was determined. Put simply, water saved through the installation of the alarming shower monitoring devices could fill 600 Olympic sized swimming pools annually.

In addition to water savings, the energy cost associated with hot water often utilised for showering is high. DeOreo and Mayer (2001) determined that $73.1 \%$ of shower end use water consumption is hot water, heated through electric, gas, solar or combination fuel source hot water systems. Therefore, $10.90 \mathrm{~kL}$ (i.e. $14.91 \mathrm{~kL} / \mathrm{hh} / \mathrm{a} \times 0.731$ ) of hot water is saved annually through the shower monitor device. The Specific Heat Capacity value for water is 4.187 kilojoules per litre $(\mathrm{kJ} / \mathrm{L})$. This means that $4.187 \mathrm{~kJ} / \mathrm{L}$ of energy is required to raise the temperature of one litre of water $(1 \mathrm{~kg}$ mass) by one degree Celsius at standard temperature and pressure. The ability of any of the heating systems to deliver this heat energy is governed by its efficiency. If a system requires twice as much energy to what can be extracted in the form of hot water then the system has an efficiency of $50 \%$. Systems range in efficiency from close to $50 \%$ for some gas systems to $99 \%$ for instantaneous gas. Based on the energy efficiency of heating systems, Specific Heat Capacity, $10.90 \mathrm{~kL}$ saving in hot water, and heating to increase the water temperature by 45 degrees Celsius, total energy saved ranged from: (a) 665 Mega joules per household per annum (MJ/hh/a) for a heat pump with electric backup system; to (b) 825-1027MJ/hh/a for solar with electric/gas backup system; to (c) 20742738MJ/hh/a for an electric system; to (d) 2600-3541MJ/hh/a for gas systems. In the sub-sample of households participating in the end use study, the majority of households had traditional electric hot water storage systems but there were still a few with other system types such as solar and heat pump. The incentivised solar panel rebate programs offered by the government may have had some influence on the uptake of solar systems. Based on the heating system stock in each of the respective sub-sample households and the calculated energy savings due to reduced hot water consumption, an average annual energy saving per household was determined as 2168MJ/hh/a or 602 kilowatt hours per household per annum (kWh/hh/a). The Gold Coast citywide consumption of energy in 2005 was 7.1 petajoules (PJ) increasing at an annual rate of 5.73\% (ABARE, 2006). Based on this base year energy use and the annual growth in power 
consumption, the 2009 energy use was estimated at 8.9PJ. As above, conservatively estimating that $50 \%$ of the determined water savings are achieved in the cities 200,000 dwelling stock, due to a range of factors (e.g. household size, etc.), a total citywide annual associated energy saving of $0.22 \mathrm{PJ}$ or $2.4 \%$ of total city energy consumption was determined.

\subsection{Monetary savings and capital pay-back}

Based on the study sample, water and energy pricing information specific to Gold Coast City, and other economic indicators, a range of variables were extracted in order to model the life cycle monetary savings resulting from the shower monitor device and the payback period. It should be noted that both water and energy savings have been modelled as these are the two direct monetary benefits evident from reduced shower water consumption. Moreover, the modelling is based on the situational context of Gold Coast City, Australia, where the study was conducted.

The variables applied to model monetary savings and capital pay-back are as follows. Annual water savings derived from this study were determined as $14.91 \mathrm{~kL} / \mathrm{hh} / \mathrm{a}$ as determined above. Gold Coast Water currently (2009/2010) charges a water consumption rate of A $\$ 2.24 / \mathrm{kL}$ (US\$2.00/kL; $1 \mathrm{AUD}=0.8904 \mathrm{USD} ; 25 / 2 / 2010$ ) which equates to an annual monetary saving of $\mathrm{A} \$ 33.40$ (US\$29.74) associated with the shower monitor. A water price inflation rate of $10 \%$ was chosen for the increase in the water consumption charge as the cost of water in Gold Coast City, and across most of Australia, has been raising excessively over the last five years due to widespread drought forcing government to invest heavily in water supply infrastructure investments (e.g. desalination plants, dams, pipelines, etc.).

Electricity prices for Gold Coast City domestic consumers are currently A $\$ 0.18843 / \mathrm{kW}$ (US\$0.16778/kW) and $A \$ 0.11319 / \mathrm{kW}$ (US\$0.10079/kW) for peak and off-peak rates, respectively (2009/2010 rates). Gas prices are A $\$ 0.02046 / \mathrm{MJ}$ (US\$0.01822/MJ) for small volume users decreasing to $\mathrm{A} \$ 0.01760 / \mathrm{MJ}$ (US\$0.01567/MJ) for higher volume users (2009/2010 rates). Given the energy savings presented above for the different heating source systems in the sub-sample and base year energy tariffs in Gold Coast City, the costs to heat water ranged from A $\$ 1.74 / \mathrm{kL}$ (US\$1.55/kL) for a solar system with gas boost to $\mathrm{A} \$ 7.90 / \mathrm{kL}$ (US\$7.03/kL) for an off-peak electric storage system. Based on the costs to heat each kilolitre of water for 
each respective heating system in each sampled household and the $10.90 \mathrm{~kL}$ of hot water saved, an annual average energy saving for the base year (2009/2010) was calculated as A $\$ 62.78 / \mathrm{hh} / \mathrm{a}$ (US\$55.90/hh/a). Similarly to water, energy cost inflation has increased at a rate in excess of $10 \%$ per annum over the last five years and is expected to continue due to costs associated with the governments' climate change policies. Thus, an energy inflation rate of $10 \%$ was again selected for discounted cash flow modelling.

Therefore the base year combined water and energy savings determined in this study was A $\$ 96.18 / \mathrm{hh} / \mathrm{a}$ $(\mathrm{US} \$ 85.64 / \mathrm{hh} / \mathrm{a})$ (water cost savings $=\mathrm{A} \$ 33.40 / \mathrm{hh} / \mathrm{a}$ and energy cost savings $=\mathrm{A} \$ 62.78 / \mathrm{hh} / \mathrm{a})$. With respect to the capital cost of the shower monitor device and associated installation costs, the average number of shower monitors installed in households was 1.3 at a purchase price of A\$75 (US\$66.78) per device. Installation of the device could be easily undertaken by the home occupier but for this study a professional plumber was employed costing A\$66 (US\$58.77) per household, regardless of number of monitors installed. This equated to an average total capital outlay of A $\$ 163.50$ (US\$145.58) per household to yield the mean $14.91 \mathrm{~kL} / \mathrm{hh} / \mathrm{a}$ water saving. There are no ongoing operational costs for the device as their battery life is around 10 years which was considered the usable life of the device.

The payback period is the time it takes for the cumulative water and energy savings to cover the capital investment of the shower monitor. A discount rate of $3 \%$ has been applied which indicates a general cost of money in the Australian context. Considering the capital investment cost, first year water and energy savings determined, water and energy price inflation as well as the discount factor, the payback period for the herein mentioned alarming visual display shower monitoring device was determined as 1.65 years. Moreover, over a 10 year life cycle period, the annualised return of investment from conservation savings generated by the capital cost of the shower monitor equates to $23.3 \%$. This attractive payback period and annualised return provide strong evidence that alarming visual display devices in the shower represent an attractive investment.

In addition to the monetary savings listed above there are a number of non-monetary benefits associated with resource consumption feedback devices such as the shower monitor discussed herein. These are discussed briefly in the next section. 


\subsection{Wider non-monetary benefits}

The modelled financial benefits and payback period for the alarming visual display monitor are substantial enough to justify their implementation across all of the urban centres in Australia as well as other urban settlements where water and energy resources are no longer secure and are rapidly increasing in price. In addition to the monetary benefits for householders for installing the device, there are a range of other nonmonetary benefits for greater society. Firstly, reduced water and energy requirements of an existing population could enable the deferment of both water and energy supply infrastructure (e.g. dams, pipeline duplications, power plants, desalination plants, etc.). Reductions in demand for such infrastructure will lessen the current inflationary pressures on prices. Lessened water consumption also means lower energy costs associated with urban water storage, production and distribution (e.g. pumping, water quality processing, desalination, etc.).

Another benefit of particular mention in the current century is climate change adaptation. Centralised water supply systems and the predominant non-renewable sources of power for heating water create substantial carbon emissions which need to be reduced to limit climate change impacts. Finally, and most importantly, the business management philosophy 'that if can't measure it, you can't manage it' has transferable relevance to resource consumption in a resource constrained world. Resource consumption awareness devices such as the one evaluated in this study assist resource users to take ownership of their usage and individually tackle their own and/or society driven conservation goals; ultimately helping to reduce the ecological footprint of the built environment.

\section{Conclusions and Futures Directions}

This paper presented findings from the GCWSEU study, namely, the evaluation of the influence of alarming visual display devices on shower end use durations, volumes and flow rates. Moreover, water and energy conservation modelling was conducted to ascertain monetary benefits as well as the payback period of such devices. Broader non-monetary benefits were also explored. The study determined that the shower visual display monitors instigated significant water and energy savings and have a respectable payback period of less than two years. The study provides empirical evidence to support the widespread 
implementation of alarming visual display shower monitors, and also provides a methodology to explore the effect of a range of other water and energy end use monitors. Through providing households with dynamically updated visual displays on a range of behaviourally influenced water and energy appliances and fixtures, residents will be better informed of their consumption rates and thus feel empowered to reasonably limit and/or maintain control over their resource consumption.

This study also illustrated that smart water metering is vital for understanding water end uses, particularly for understanding the characteristics of shower end use events. Future research directions associated with this component of the research program, include: (1) to examine the change in shower water conservation practices with time (i.e. longitudinal study); (2) conduct interviews with residents participating in the study to explore how they responded to the device; (3) examine the effect of visual display monitors and/or alarming devices on other domestic end use events (e.g. tap fixtures); (4) evaluate shower event water temperature relative and cumulative frequency distributions to better model heating requirements; (5) directly monitor water heating power consumption associated with shower end use events; and (6) further model water and energy conservation with a greater sample across different Australian urban centres.

Future research associated with the GCWSEU study is also discussed as follows. Firstly, research is currently underway to examine the predictive power of descriptive (i.e. education level, income, etc.), infrastructure (i.e. stock survey) and qualitative variables (i.e. attitudes, perceptions, etc.) on water end use in domestic households. Secondly, recycled water will be commissioned and supplied to residents in the Pimpama Coomera region of Gold Coast City in late 2009, and a summer end use data collection phase (December-February 2009) will be undertaken to establish the uptake of recycled water at the end use level. This, combined with previous end use data, will provide 'before and after' end use results of the implementation of recycled water. This data will assist in verifying end use assumptions made in the planning phases of the Pimpama Coomera development. Thirdly, the impact of education or awareness as a demand management measure will also be tested within the study. Residents participating in the research will be provided with their unique end use data as well as targeted suggestions for reducing high end uses within their homes. This study seeks to establish if water consumption behaviours alter as a result of the provided information. 
Another component of the research program is the establishment of diurnal patterns for both single and dual reticulated households in the Gold Coast. Dual reticulated households will have two separate diurnal patterns for both potable and recycled water demand. Such diurnal patterns will be determined at an end use level, thus providing a comprehensive understanding of water consumption at a given time, which provides indications on how to affect peak loading to the urban water system. The above stated components of the research program will culminate in the development of a comprehensive domestic end use model for the Gold Coast as well as evidence that supports, or otherwise, the effect of WDM measures (principally dual reticulation and awareness/education initiatives) for conserving previous precious potable water supplies. Such models and findings could be adapted for both national and international applications and policy formulation.

\section{References}

Abrahamse W, Steg L, Vlek C, Rothengatter T. The effect of tailored information, goal setting, and tailored feedback on household energy use, energy-related behaviors, and behavioral antecedents. Journal of Environmental Psychology 2007; 27(4): 265-276.

Arroyo E, Bonanni L, Selker T. Waterbot: exploring feedback and persuasive techniques at the sink. In: Proceedings of the SIGCHI 2005 conference on human factors in computing systems. Portland; 2005. 631-639.

Australian Bureau of Agricultural and Resource Economics (ABARE). Australian energy consumption by industry, 1974-75 to 2004-05, June. Canberra; 2006.

Bechtel RB, Corral-Verdugo V, Pinheiro JQ. Environmental belief systems: United States, Brazil, and Mexico. Journal of Crosscultural Psychology 1999; 30: 122-128.

Birrell B, Rapson V, Smith F. Impact of Demographic Change and Urban Consolidation on Domestic Water Use. Melbourne: Water Services Association of Australia Inc.; 2005.

Britton T, Cole G, Stewart R, Wisker D. Remote diagnosis of leakage in residential households. Water 2008; 35(6): 89-93. 
Chambers VK, Creasey JD, Glennie, EB, Kowalski M, Marshallsay D. Increasing the value of domestic water use data for demand management - summary report. Wiltshire: WRc plc; 2005.

Commonwealth Scientific and Industrial Research Organisation (CSIRO). Climate Change in Australia: Technical Report 2007. Melbourne: CSIRO; 2007.

Corral-Verdugo, Bechtel R, Fraijo-Sing B. Environmental beliefs and water conservation: An empirical study. Environmental Psychology 2002; 23: 247-257.

Darby S. The Effectiveness of Feedback on Energy Consumption. Environmental Change Institute, University of Oxford; 2006.

DeOreo WB, Mayer PW. The End Uses of Hot Water in Single Family Homes from Flow Trace Analysis, 2001: Aquacraft Inc. Report, http://www.aquacraft.com.

Dobson JK, Griffin JD. Conservation Effect of immediate electricity cost feedback on residential consumption behaviour. In: Proceedings of the 7th ACEEE Summer Study on Energy Efficiency in Buildings. Washington, DC; 1992. p. 33-35.

Fischer C. Feedback on household electricity consumption: a tool for saving energy? Energy Efficiency 2008; 1(1): 79-104.

Hauber-Davis G, Idris E. Smart water metering. Water 2006; 33(3): 56-59.

Hearn B. Benchmarking water use on farm: if you don't measure it, you can't manage it. In: Proceedings of the 9th Australian Cotton Conference. Gold Coast; 1998. p. 519-529.

Idris E. Smart metering: a significant component of integrated water conservation system. In: Proceedings of the 1st Australian Young Water Professionals Conference. Sydney: International Water Association; 2006.

Inman D, Jeffrey P. A review of residential water conservation tool performance and influences on implementation effectiveness. Urban Water Journal 2006; 3(3): 127 - 143.

Kappel K, Grechenig T."show-me": water consumption at a glance to promote water conservation in the shower. In: Proceedings of the 4th international conference on persuasive technology. Claremont; 2009.

Kenney D, Goemans C, Klein R, Lowrey J, Reidy K. Residential water demand management: lessons from Aurora, Colorado. Journal of the American Water Resources Association 2008; 44(1): 192-207. 
Mayer P, DeOreo W, Towler E, Martien L, Lewis D. Tampa Water Department residential water conservation study: The impacts of high efficiency plumbing fixture retrofits in single-family homes. Tampa: Aquacraft, Inc Water Engineering and Management; 2004.

Mayer PW, DeOreo WB. Residential End Uses of Water, Boulder: Aquacraft, Inc. Water Engineering and Management; 1999.

McClelland L, Cook S. Energy conservation effects of continuous in-home feedback in all-electric homes. Journal of Environmental Systems 1979-1980; 9(2): 169-173.

Midden CJH, Kaiser FG, McCalley LT. Technology's four roles in understanding individuals' conservation of natural resources. Journal of Social Sciences 2007; 63(1): 155-174.

Nieswaidomy ML. Estimating Urban Residential Water Demand: Effects of Price Structure, Conservation, and Education. Water Resources Research 1992; 28: 600-615.

Taverner Research. Survey of Household Water Attitudes. Surry Hills: Taverner Research; 2005.

Turner A, White S, Beatty K, Gregory A. Results of the largest residential demand management program in Australia. Sydney: Institute for Sustainable Futures, University of Technology; 2005.

Ueno T, Inada R, Saeki O, Tsuji K. Effectiveness of displaying energy consumption data in residential houses: analysis on how the residents respond. In: Proceedings of the 2005 summer study of the European Council for an energy efficient economy. Stockholm: ECEEE; 2005. p. 1289-1299.

Ueno T, Sano F, Saeki O, Tsuji K. Effectiveness of an energy-consumption information system on energy savings in residential houses based on monitored data. Applied Energy 2006; 83(2): 166-183.

Waisbord S. Family Tree of Theories, Methodologies and Strategies in Development Communications. Report prepared for The Rockefeller Foundation. New York; 1999.

Water Services Association of Australia (WSAA). MRWA WSA 03 Dual Water Supply Systems: Version 1.1. WSAA, Melbourne Retail Water Agencies Edition of the Water Supply Code of Australia; 2002.

Webb T. Towards Sustainable Water Futures in Western Sydney. In the pipeline: a symposium -new directions in cultural research on water. Sydney: University of Western Sydney; 2007.

Willis R, Stewart RA, Panuwatwanich K, Capati B, Giurco D. Gold Coast domestic water end use study. Water 2009; 36(6): 79-85.

Wood G, Newborough M. Dynamic energy-consumption indicators for domestic appliances: environment behaviour and design. Energy and Buildings 2003; 35: 821-841. 


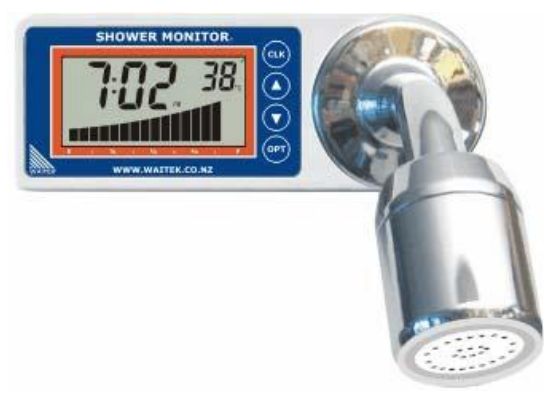

Fig. 1. Alarming visual display device.

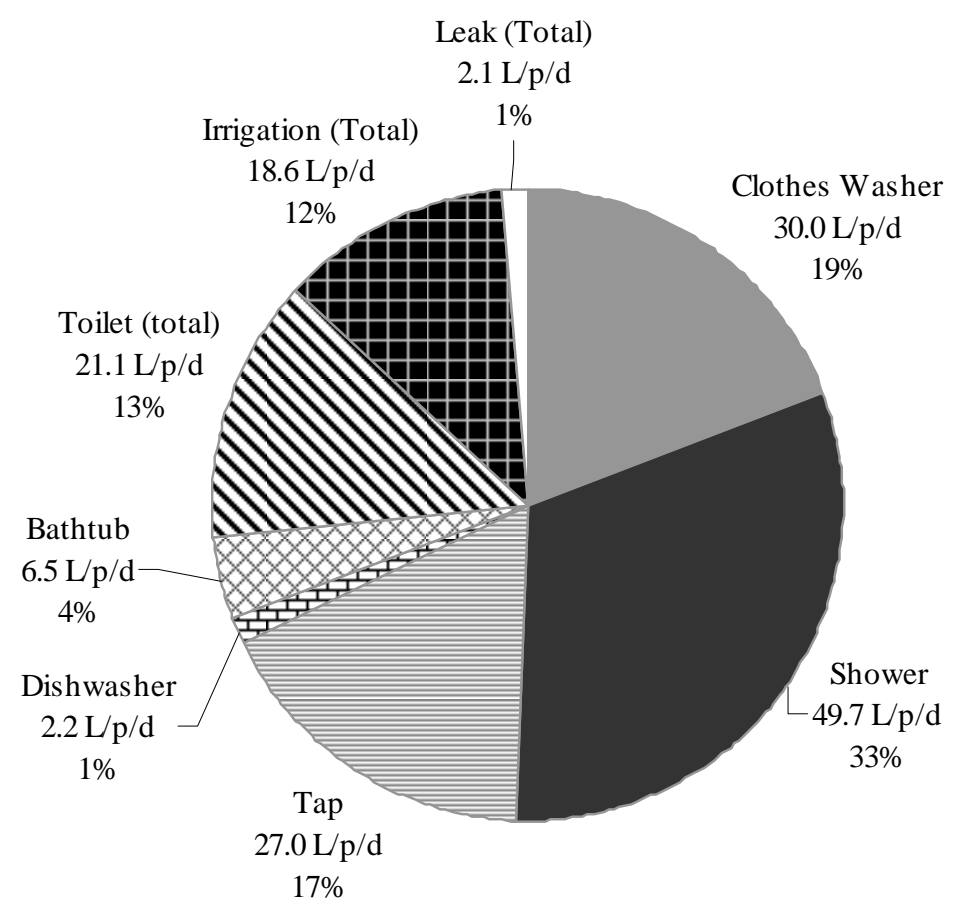

Fig. 2. Sample end use break down: winter pre-retrofit (N=151). 


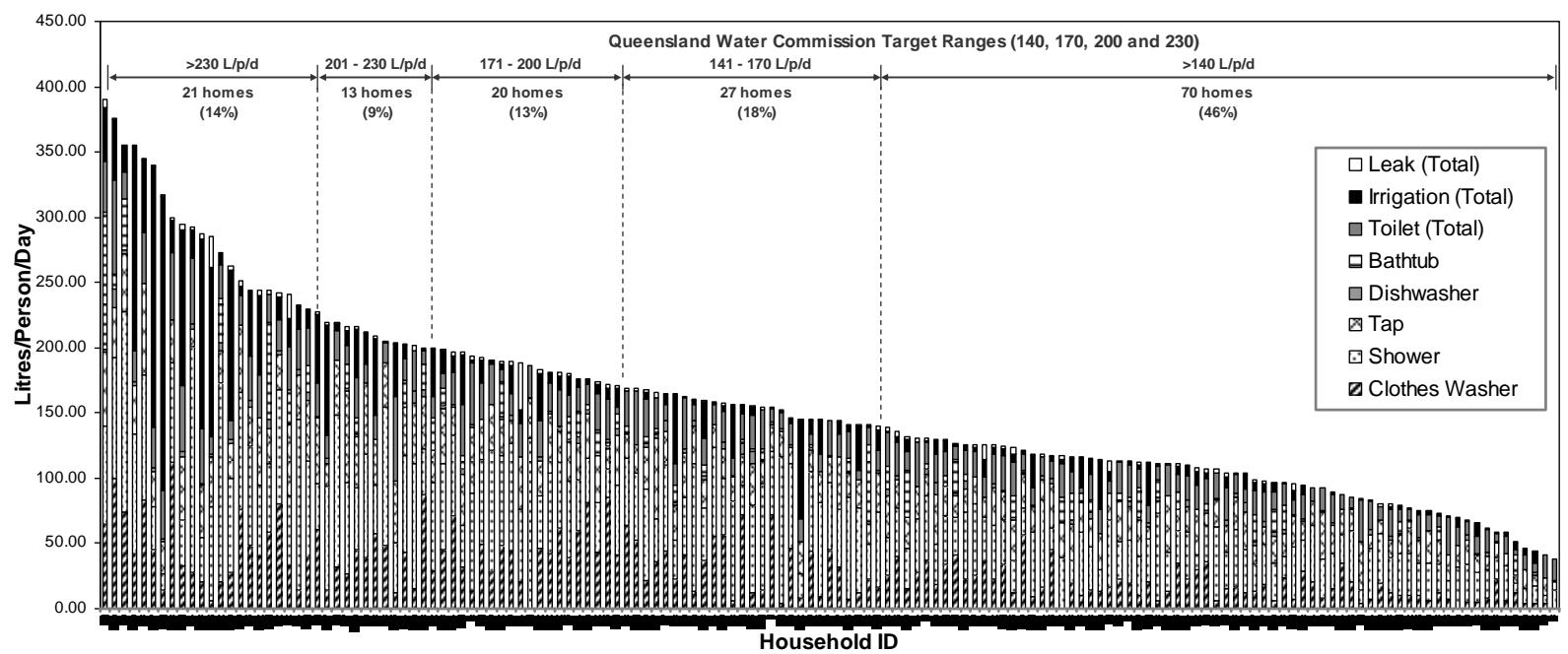

Fig. 3. Sample household end use distribution: winter pre-retrofit ( $N=151)$.

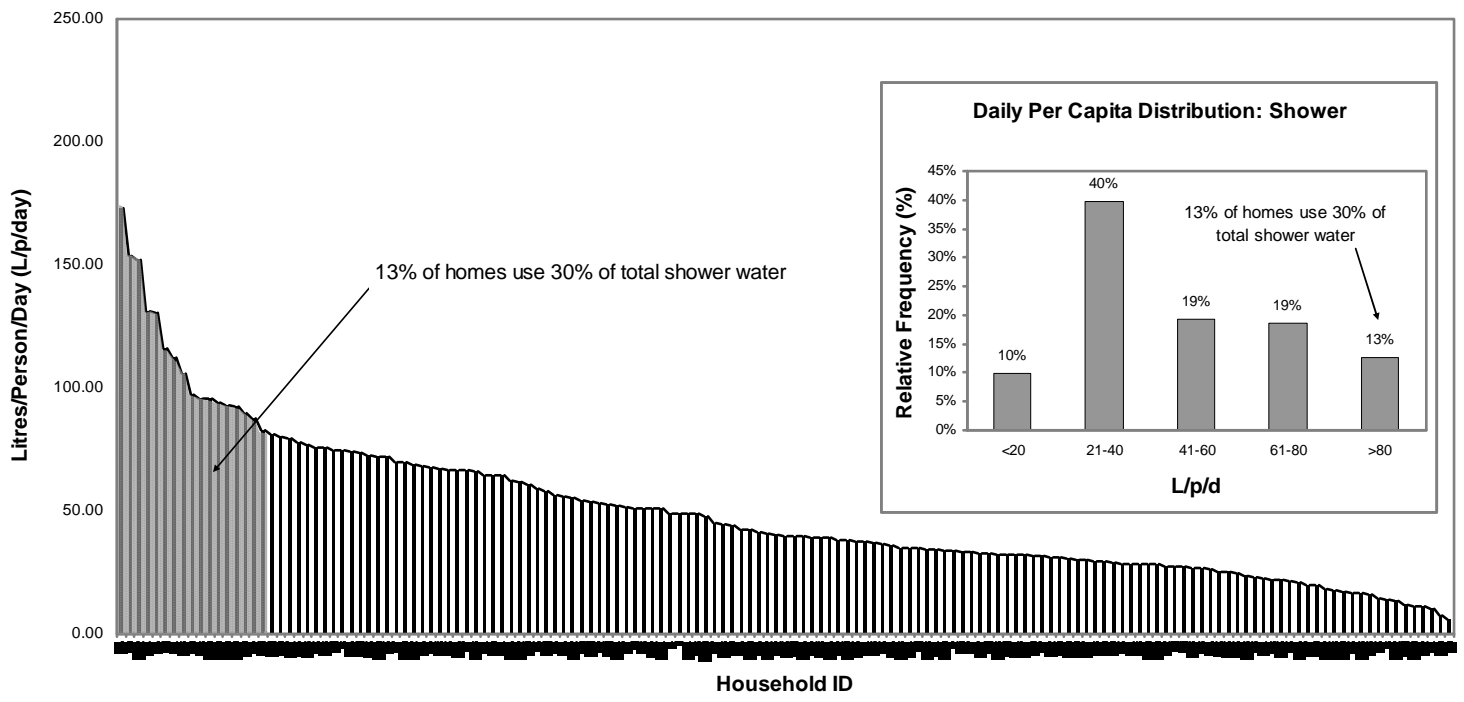

Fig. 4. Sample shower end use distribution: winter pre-retrofit (N=151). 


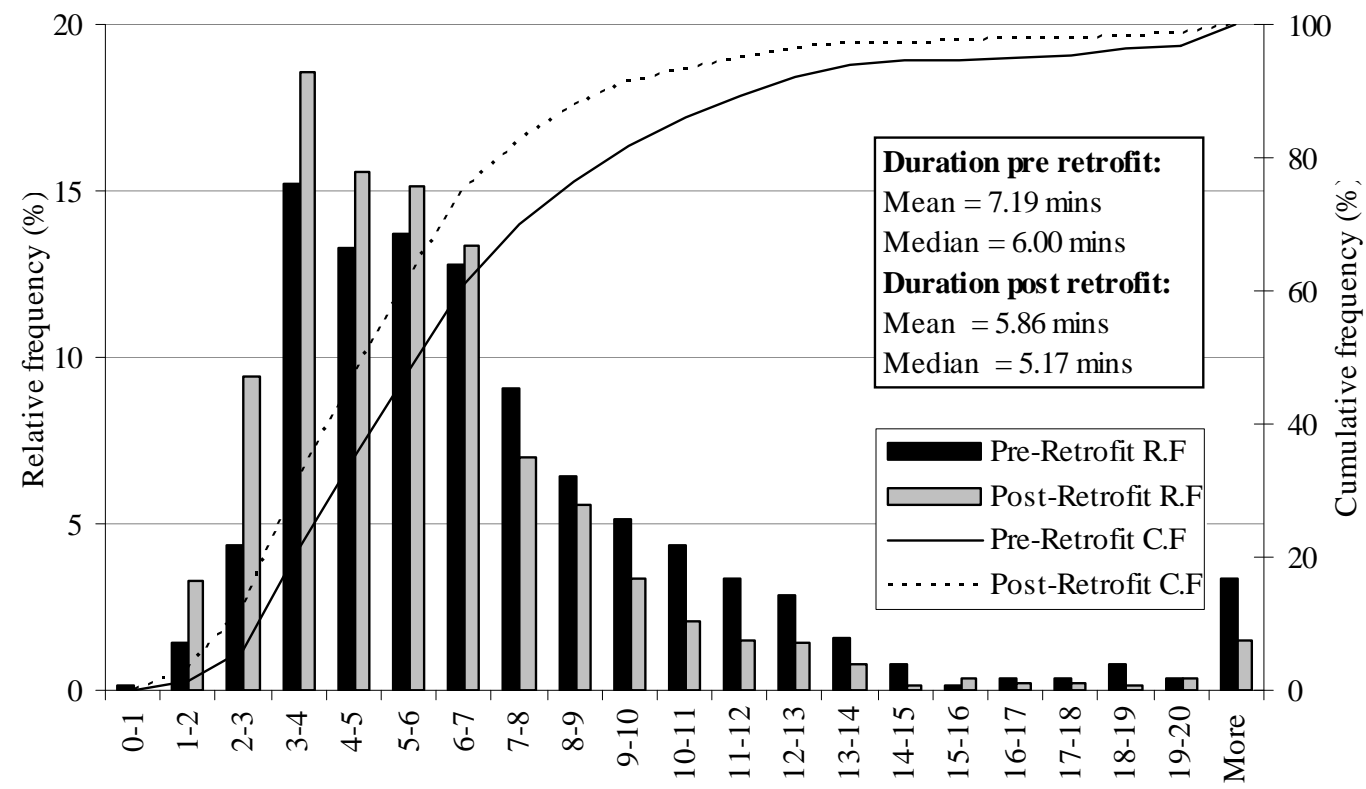

Duration event clusters (minutes)

Fig. 5. Sample pre- and post- monitor retrofit shower event duration frequency distribution.

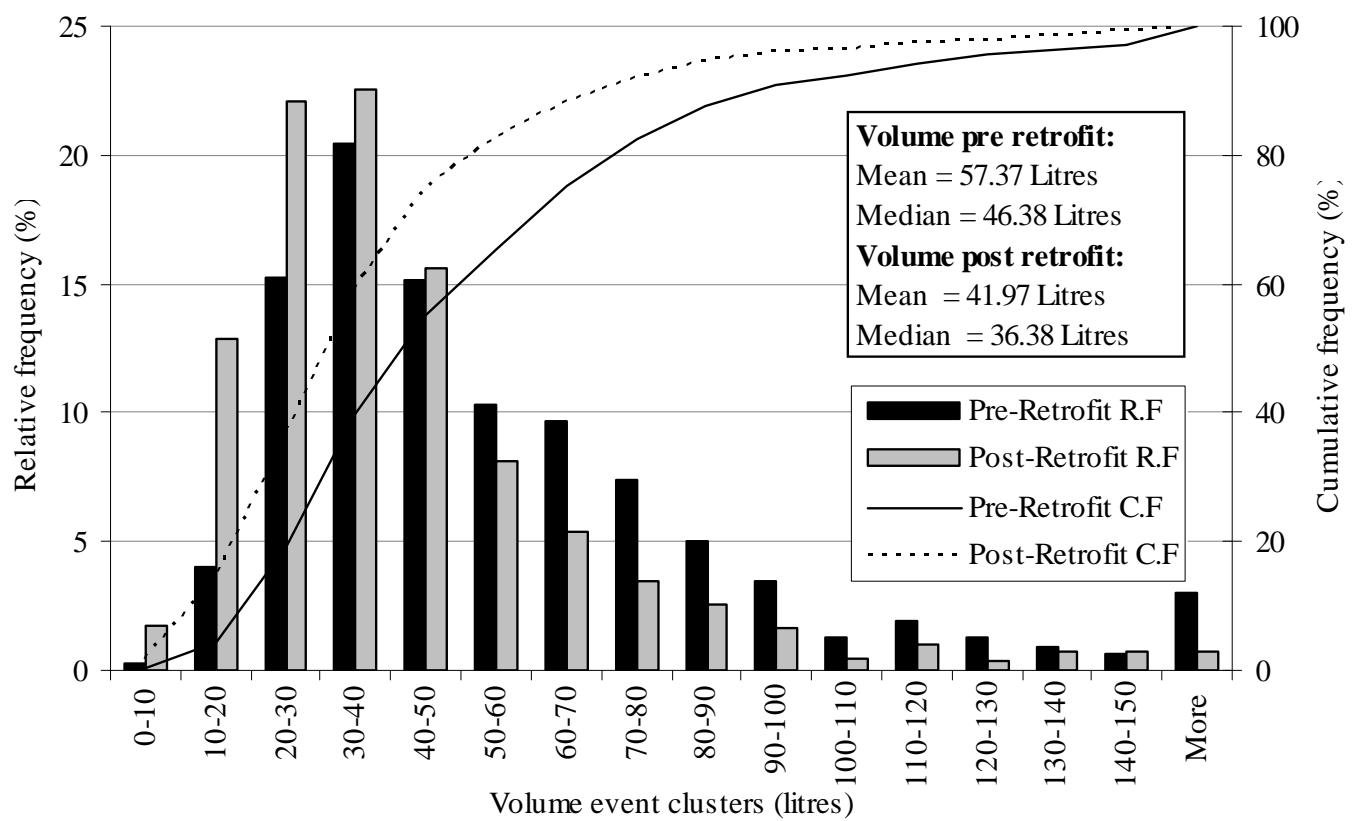

Fig. 6. Sample pre- and post- monitor retrofit shower event volume frequency distribution. 


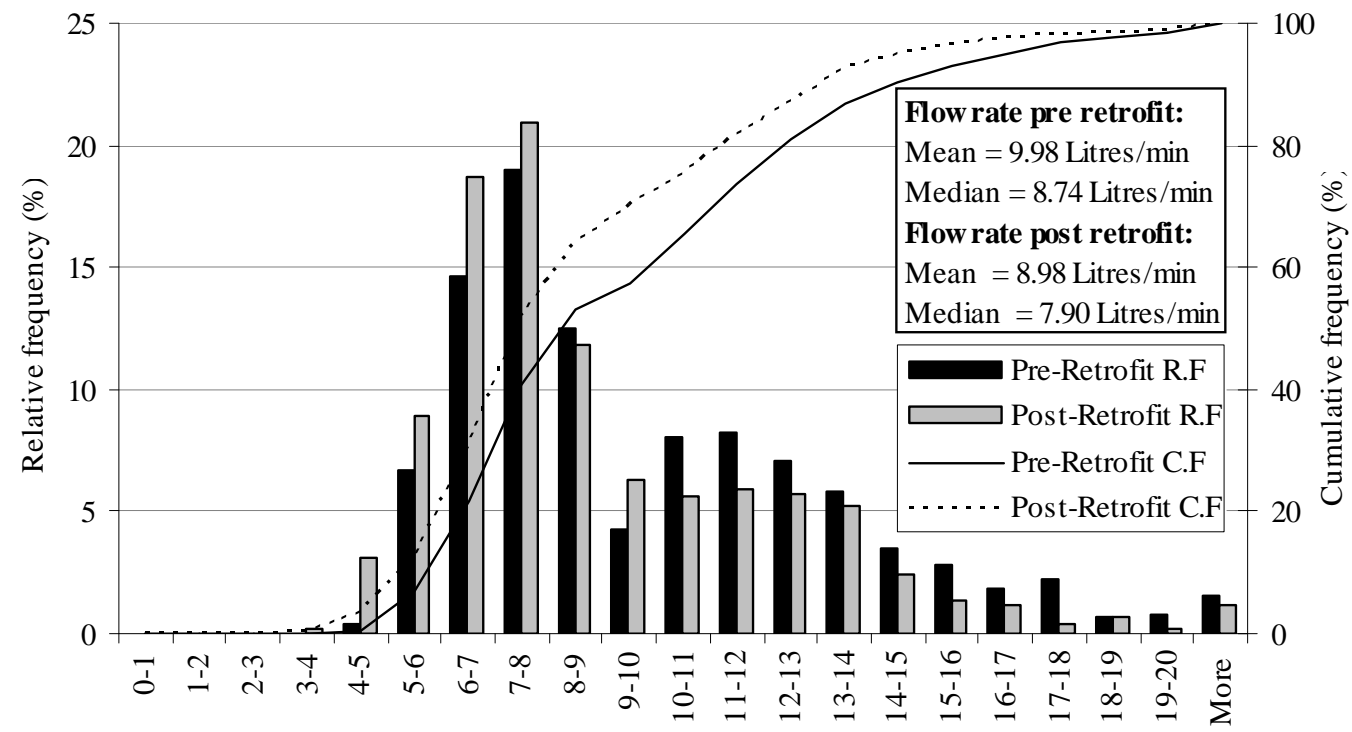

Event flow rate (litres/minute)

Fig. 7. Sample pre- and post- monitor retrofit shower event flow rate frequency distribution. 
Table 1

Independent sample t-test for equality of means.

\begin{tabular}{|c|c|c|c|c|c|c|c|c|c|c|c|c|}
\hline \multirow[t]{2}{*}{$\begin{array}{l}\text { Event } \\
\text { description }\end{array}$} & \multirow[t]{2}{*}{$\begin{array}{l}\text { Variance } \\
\text { assumption }\end{array}$} & \multicolumn{2}{|c|}{$\begin{array}{l}\text { Levene's test for } \\
\text { equality of } \\
\text { variances }\end{array}$} & \multirow[b]{2}{*}{$\mathrm{t}$} & \multirow[b]{2}{*}{ df } & \multicolumn{3}{|c|}{ t-test for equality of means } & \multirow[b]{2}{*}{$\begin{array}{r}\text { Sig. } \\
\text { (2-tailed) }\end{array}$} & \multirow[b]{2}{*}{$\begin{array}{l}\text { Std. error } \\
\text { difference }\end{array}$} & \multicolumn{2}{|c|}{$\begin{array}{l}\text { 95\% confidence } \\
\text { interval of the } \\
\text { difference }\end{array}$} \\
\hline & & $\mathrm{F}$ & Sig. & & & $\begin{array}{r}\text { Mean } \\
\text { (pre-retrofit) }\end{array}$ & $\begin{array}{r}\text { Mean } \\
\text { (post- retrofit) }\end{array}$ & $\begin{array}{r}\text { Mean } \\
\text { difference } \\
\text { (pre- vs. post) }\end{array}$ & & & Lower & Upper \\
\hline \multirow{2}{*}{ Duration (min) } & Assumed & 27.14 & .000 & 6.70 & 1631 & 7.19 & 5.86 & 1.34 & .000 & .200 & .95 & 1.73 \\
\hline & Not assumed & & & 6.62 & 1469 & 7.19 & 5.86 & 1.34 & .000 & .202 & .94 & 1.73 \\
\hline \multirow{2}{*}{ Volume (L) } & Assumed & 39.34 & .000 & 9.11 & 1632 & 57.37 & 41.97 & 15.40 & .000 & 1.691 & 12.08 & 18.72 \\
\hline & Not assumed & & & 8.93 & 1338 & 57.37 & 41.97 & 15.40 & .000 & 1.724 & 12.02 & 18.78 \\
\hline \multirow{2}{*}{$\begin{array}{l}\text { Flow rate } \\
\text { (L/min) }\end{array}$} & Assumed & 14.98 & .000 & 5.82 & 1632 & 9.98 & 8.98 & 1.00 & .000 & .171 & .66 & 1.33 \\
\hline & Not assumed & & & 5.78 & 1556 & 9.98 & 8.98 & 1.00 & .000 & .172 & .66 & 1.33 \\
\hline
\end{tabular}

